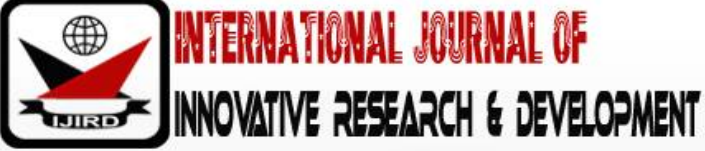

ISSN 2278 - 0211 (Online)

\section{Application of the Taguchi Method in the Investigation of Influential Heat Treatment Factors in Steel Wires}

\author{
Cristie Diego Pimenta \\ Professor, Department of Business, Dehoniana College, Sao Paulo, Brazil \\ Messias Borges Silva \\ Professor, Department of Production, University of Guaratingueta, Sao Paulo, Brazil \\ Rose Lima de Morais Campos \\ Professor, Department of Business, ITES College, Sao Paulo, Brazil \\ Walfredo Ribeiro de Campos Junior \\ Professor, Department of Marketing, College ESPM, Sao Paulo, Brazil
}

\begin{abstract}
:
Statistical methods have been used to improve processes and accelerate industrial technological development. This study contributed to the investigation of the causes that can alter the mechanical properties in steel wires during the tempering process only for diameters $3.00 \mathrm{~mm}$ and $5.00 \mathrm{~mm}$, used in the manufacture of valve springs and clutch for automobile followup. This research will show the application of the Taguchi Method, Desirability Method and Generalized Reduced Gradient to investigate the mechanical properties tensile strength, area reduction and hardness, in SAE 9254drawn steel wires. Data were generated from application of Design of Experiments Methodology (by means of the Minitab Statistical Software) and the results revealed which variables were considered influential. The Multiple Linear regressions were also used to create mathematical models of the process. It was concluded that the tempering temperature and diameter are the factors that cause the increase or reduction of the variable responses' tensile strength and hardness of drawn steel wire SAE 9254 during the tempering process and that the factors investigated have not influence on the variable response area reduction. It was observed that with the application of the Taguchi Method it was possible to reduce the number of experiments to be carried out and thus it was possible to reduce the costs significantly. If instead of using the Taguchi Method a complete matrix $2^{4}$ would be required to perform 16 experiments with at least one repetition for each situation (so that it was possible to calculate the standard error). With this, 32 experiments would be carried out. In this case, with the use of the Taguchi method, the quantity of experiments was reduced to 8 experiments (without the need repetition), which represented the reduction of $75 \%$ in the costs of experimentation. It has been found that the statistical methods and optimization methods studied in academic environments and often employed only on a small scale of production, in research laboratories or in simulators in universities, can also be applied In an industrial environment of large scale production, contributing to the solution of complex problems and being of important value for future technological innovations in the industries.
\end{abstract}

Keywords: Taguchi method, multiple linear regressions, generalized reduced gradient, desirability function

\section{Introduction}

Currently the industries have sought increasingly to cost reduction and variability. With this, the application of statistical methods in manufacturing processes and services has been constituted in important factor and differential between companies. The practice of applications of statistical methods is now in your time of greatest use. In manufacturing, process industries, hospitals and services, statistical thinking is being used to decrease costs, reduce defects and control the variability.

Statistical studies are not used only for data analysis, but primarily for the planning of experiments in which these are collected. For more sophisticated than is the analysis that, the lack of planning can cause great failure and, in many cases, much time can be lost until the researcher realizes that he should have planned their experiments properly. The Taguchi method allows you to determine the best combination of factors and interactions that influence the behaviour of the response variable of the given process. Generally, the use of this method requires the least amount of sampling, reducing the cost of testing, without great damage to the conclusions reached (ROSA et al., 2009). This article depicts the application of as a statistical tool for planning experiments and its main objective is to investigate the factors and interactions that influence the process of hardening heat treatment in SAE 9254 steel wires.

This work used Taguchi Method as the main statistical method for planning experiments, but also used multiple regression methods to model statistically the process, Desirability and Generalized Reduced Gradient to optimize the process through the appropriate adjustments of the factors. 


\section{Literature Review}

\subsection{Thermal Treatment and Mechanical Tests}

\subsubsection{Quenching and Tempering}

Quenching is related to sudden cooling after heating steel to the aesthetic zing temperature and aims to obtain a microstructure that gives mechanical properties, such as hardness and limit of high resistance to specific applications that require this condition. During the cooling stage in tempering the temperature drop promotes structural changes that result in the emergence of internal tensions and so it is necessary the realization of tempering (CALLISTER, 2012). The temper can be:

For calls, the heating comes from calls directed at play, by means of a blowtorch or other instrument, and thus can be partly tempered;

- Induction Hardening, heating is obtained by electrical induction, followed by a sudden cooling, typically in water;

- Surface Hardening, heating surface only through induction or flame until the aesthetic zing, followed by a Quick cooling;

- Overall, total heating Quenching of the piece to temperature then cooling austenitizing, in predetermined medium. The tempering involves a series of micro structural transformations that tend to thermodynamic equilibrium. It is, therefore, a thermally activated process and thus direct function of time and temperature of process. As the martensite is extremely hard and brittle, so pieces in these conditions may bite. Therefore, the tempering to achieve proper values of mechanical strength, toughness and strain relief (GABARDO, 2008). Temperature drop during cooling, at tempering, promotes structural transformations which lead to internal stress appearance and therefore it is necessary a tempering treatment. The tempering process is carried out complementarily to Quenching, being particularly important in steel manufacturing for springs. It consists in heating the tempered material between $250{ }^{\circ} \mathrm{C}$ and $650{ }^{\circ} \mathrm{C}$ for a certain time to increase ductility and elasticity (CALLISTER, 2012).

\subsubsection{Tensile Strength Test}

Fatigue is a form of failure that occurs in structures or components that are subject to dynamic stresses and swaying. Under these circumstances, this type of failure usually occurs after a long period of repeated stress or deformation cycles, there is the need of the control relative to limit mechanical properties tensile strength and hardness, which are fundamental characteristics for prevention of fatigue failures (CALLISTER, 2012).

Berger e Kaiser (2006), said that whereas the springs are used as structural elements that are subject to the limit of tensile or compression, the wire itself must be able to withstand the traction or compression stresses the coil springs respond to strength of external compression with a torsion strain caused by torsion of active coils in spring. The wire for your time must be able to resist the torsional stresses arising, requiring the testing of tensile strength limit for this monitoring. In a test of tensile strength limit the body of proof shall be on the head of a testing machine that applies an effort which tends to lengthen it up to the break, being measures the deformation by means of a device called a strain gauge. The test is performed on a body of evidence with standardized dimensions, so that the results obtained can be compared, reproduced and measured on the machine itself. Usually the test occurs until the break of the material (what ranks as destructive) and allows you to measure the resistance of the material to deform plastically until the break, at which point you get the limit of tensile strength (CHIAVERINI, 2012).

Iron and steel industries is very used the universal testing machine of traction (Figure 1) and it is common for the units of force used are kilogram-force per square millimetre $\left(\mathrm{kgf} / \mathrm{mm}^{2}\right)$ or MegaPascal (MPa). The main technical standard used for the execution of mechanical tests is drafted by the Organization ASTM (American Society for Testing and Materials).

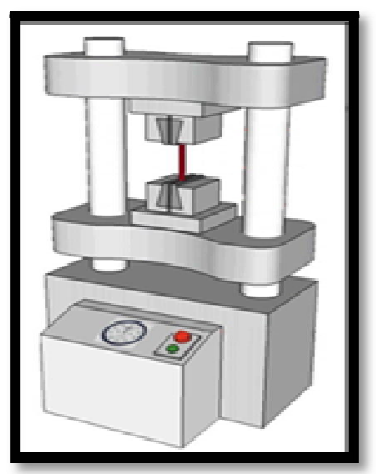

Figure 1: Testing Machine. Brinell Hardness (BH) Method Illustration

\subsubsection{Area Reduction Test}

The spring material should have the following characteristics: high yield stress limit (yield stress), to support substantial loads without permanent deformation; low modulus of elasticity for elastic deformations; high fatigue limit, as 
in the case of the auto industry, virtually all the springs fail by fatigue, which leads to the rupture at some point of concentration of voltage; high resistance to shock, especially in automotive springs (CHIAVERINI, 2012).

Spring steels have a function that requires that the same report high resilience, that is, the ability to absorb energy when the material is deformed elastically and, later, with the removal of the load, enabling the release of energy. The property associated with the modulus of resilience can be measured by the yield and area reduction (PAULA, 2013).

Contraction is set as the attribute presented by certain materials to suffer large plastic transformations before your breakup when subjected to tension. In specimens of steel the contraction is measured by the reduction in crosssectional area that occurs before the break. The contraction is given by the ratio between the change in cross-sectional area of body of proof (initial area - final area) / initial area (Figure 2). The contraction or area reduction is usually expressed as a percentage, showing how much of the cross-sectional area of the resistive body of proof section was reduced after the application of force $(F)$ on the threshold test of tensile strength, as shown in Figure 3.

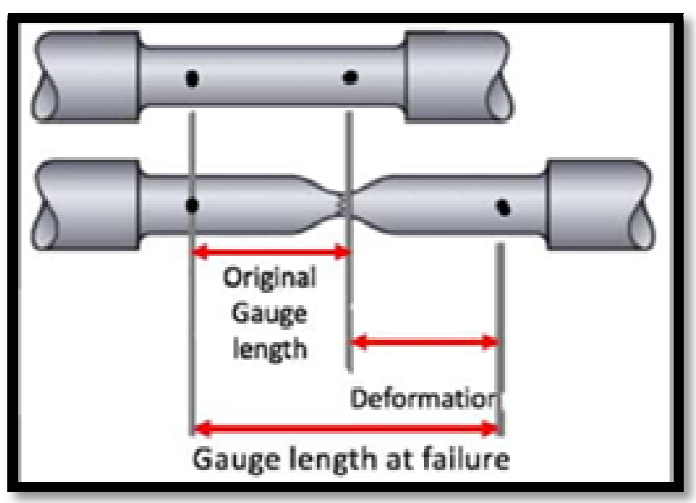

Figure 2: Area Reduction after Rupture of the Body of Evidence

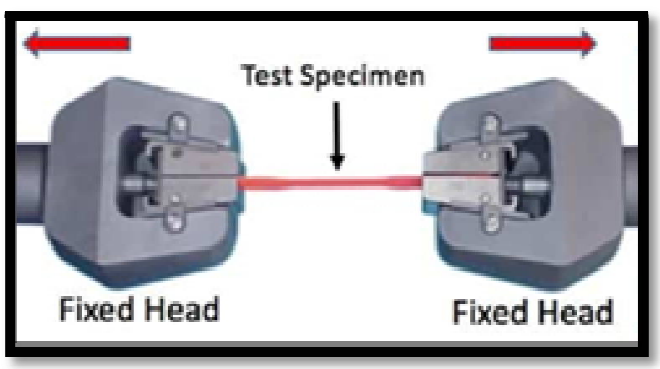

Figure 3: Area Reduction after Rupture of the Body of Evidence

\subsubsection{Hardness Test}

According to Callister (2012), hardness is a metal resistance measure to penetration. The most common methods to determine a metal hardness are Brinell, Vickers and Rockwell. In this research, only the Brinell method (BH) is used. Brinell hardness values (BH), as shown in Figure 4, are calculated by dividing applied load by penetration area. The diameter penetrator (D) is a hardened steel ball for materials of medium or low hardness, or tungsten carbide for high hardness materials. The test machine has a light microscope which makes the circle diameter measurement $(\mathrm{d}$, in $\mathrm{mm})$, which corresponds to the spherical cap projection printed on the sample. Brinell hardness (BH) is given by the applied load ( $\mathrm{P}$, in kgf) divided by the print area, as shown in expression 1.

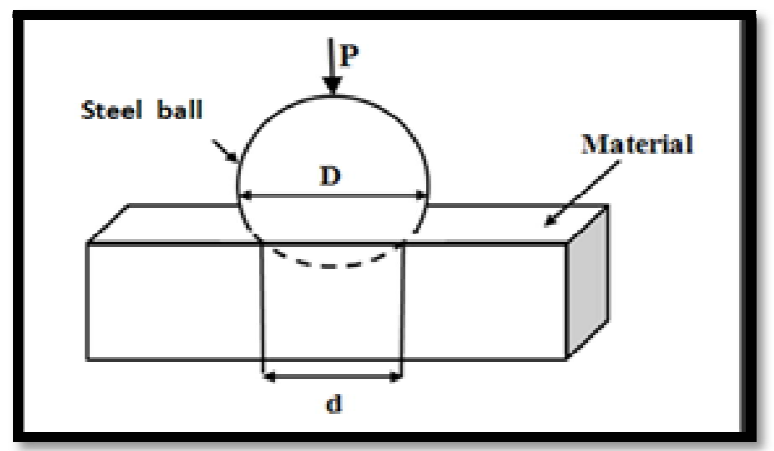

Figure 4: Brinell hardness (BH) Method Illustration 


$$
B H=\frac{2 P}{\pi D\left(D-\sqrt{D^{2}}-d^{2}\right)} \quad\left[\mathrm{kgf} / \mathrm{mm}^{2}\right]
$$

\subsection{Statistical Methods}

\subsubsection{Taguchi Method and Significance test}

As demonstrated by Lima et al. (2011), the design of experiments is the most appropriate methodology to study various process factors and the complexity of their interactions, in order to increase the probability of solving problems through statistical analyses. This methodology is considered to be powerful to improving quality and productivity in recent years has been increasingly applied in world industry, mainly for the automotive segment (SILVA; SILVA, 2008).

As shown by Souza et al. (2011); Robin et al. (2010) and Rosa et al. (2009) the design of experiments is used to define which data and under what conditions must be collected during the trial to ensure better accuracy in statistic analysis of results. The application of this method in your traditional way, complete with $2 \mathrm{k}$, where $\mathrm{k}$ represents the amount of factors investigated and a full replica requires $2 \times 2 \times 2 \times \ldots . .2=2 \mathrm{k}$ Observations and this implies a large number of experiments which can make the study unfeasible due to the high costs of testing (NETO et al., 2007).

Between 1950 and 1960 Genichi Taguchi developed and applied the method robust design in many industries, including electronics and the automotive (SOUZA et al., 2011).

The Taguchi method enables the investigation of process input variables and their interactions with small number of experiments. This method makes it possible to significantly reduce the quantity of experiments originally planned, because it is a structure composed of fractional saturated arrays which provides great reduction of costs related to experimentation, can be implemented in situations involving products and/ or processes.

Taguchi methodology is defined by two important parameters:

- $\quad$ Reduction in variability, i.e., quality engineering job in product or process seeking continuous improvement and less waste for the company;

- Application of the strategic planning, aiming at the development of new research, aiming at the optimization of the process and the reduction of experiments in real situations, resulting directly in cost reduction with experimentation.

For definition of the experiments, are used several orthogonal arrangements (experimental arrays), generally referred to as $L n$, where " $n$ " represents the number of experiments to be carried out. The most common are the arrays $L_{4}$, $L_{8}, L_{9}, L_{12}, L_{16}, L_{18}, L_{27}$ e $L_{32}$ for factors of two and three levels. The matrices are used in the design of experiments for the purpose of studying the significant variables and their interactions that occur at the same time.

Taguchi has defined that the choice of orthogonal arrangement can be made by the method of counting the number of degrees of freedom, which is the number of factors but one, and developed linear and triangular tables graphics that allow the identification of interactions and allocation of factors (ROSS, 1995).

The Taguchi method makes use of the signal-to-Noise $(\mathrm{S} / \mathrm{N})$. It is a logarithmic function used to optimize the process or product design, minimizing variability. It is derived from the communications industry, where it has been used for nearly a century, representing the relationship between sensitivity and variability of a given system of measurement. As demonstrated by Souza et al. (2011) there are three types of relationship (S/ N):

- $\quad$ Smaller is better (the lower the value of the response, the better it is for the process);

- Greater is better (the higher the value of the response, the better it is for the process);

- Nominal is better (the closer the specification, the better it is for the process).

ANOVA is a statistical method used to interpret the experimental data in decision making and to statistically test the averages of the results in their different conditions (MONTGOMERY; RUNGER, 2009).

Using ANOVA, it is possible to compare three or more factors and their interactions, and can be used in addition to the Taguchi method, using the F test, to prove the factors that are really significant in the process (ROSA et al., 2009; CORREIA; CARDOZA, 2011).

As Rosa et al. (2009) to analyze statistically the results obtained through design of experiments the most recommended method is the analysis of variance (ANOVA), by means of which, you can compare two or more factors and also test the significance of the regression, making use of the F-test to establish which factors and interactions between them are really significant in the process. From the parameters calculated on ANOVA can create or validate statistical models, as well as calculate the coefficients necessary for process modeling through multiple regression can be linear, quadratic or interaction terms.

\subsubsection{Multiple Linear Regression and Desirability Method}

Montgomery and Runger (2003) state that multiple linear regression is used for situations involving more than one regressor, and the models can include interaction effects. An interaction between two variables can be represented by a cross term, for if we assume that $\mathrm{x}_{3}=\mathrm{x}_{1} \mathrm{x}_{2}$ and $\beta_{3}=\beta_{12}$, then the model, including interaction terms, will be as shown in expression 2.

$$
Y=\beta_{0}+\beta_{1} x_{1}+\beta_{2} x_{2}+\beta_{3} x_{3}+\ldots+\varepsilon
$$

In this expression, $\mathrm{Y}$ is the dependent variable; the independent variables are represented by $x_{1}, x_{2}, \ldots, x_{n}$ and $\varepsilon$ is the random error term. The term "linear" is used because the equation is a linear function of the unknown parameters 
$\beta_{0}, \beta_{1}, \beta_{2}$ and $\beta_{\mathrm{n}}$. In this model, the parameter $\beta_{0}$ is the plane intersection; $\beta_{1}, \beta_{2}$ and $\beta_{\mathrm{n}}$ are the regression partial coefficients.

The desirability method is a method used for determining the best conditions for process adjustment, making possible simultaneous optimization of multiple responses. This being so, the best responses conditions are obtained simultaneously minimizing, maximizing or seeking nominal values of specifications, depending on the most convenient situation for the process (WANG, WAN, 2009).

Each one of responses $\left(Y_{1}, Y_{2} \ldots Y_{k}\right)$ of original set is transformed, such that $d_{i}$ belongs to interval $0 \leq d_{i} \leq 1$. The $d_{i}$ value increases when the i response approaches the imposed limits. The expression 3 is used to find the D global index, from combination of each one response processed through a geometric mean.

$$
D=\left(d_{1}\left(Y_{1}\right) \times d_{2}\left(Y_{2}\right) \ldots \times d_{k}\left(Y_{k}\right)\right)^{\frac{1}{k}}
$$

As a result of geometric mean represented by expression 3, the value D evaluates, in a general way, the levels of the combined set of responses. It is an index also belonging to interval $[0,1]$ and will be maximized when all responses approach as much as possible of its specifications. The closer of one $D$ is, the closer the original responses will be of their respective specification limits. The general optimal point of system is the optimal point achieved by maximizing the geometric mean, calculated from individual desirability functions (PAIVA, 2008). According to Paiva (2008), advantage of using geometric mean is to make the overall solution is achieved in a balanced way, allowing all responses can achieve the expected values and forcing algorithm to approach the imposed specifications.

As shown by Derringer and Suich (1980), the algorithm will depend on the optimization type desired for response (maximization, minimization or normalization) of desired limits within the specification and the amounts (weights) of each one response, which identifies the main characteristics of different optimization types, as follows:

- Minimize Function: The desirability function value increases as the original response value approaches a minimum target value;

- Normalize Function: When response moves toward the target, the desirability function value increases;

- Maximize Function: The desirability function value increases when the response value increases.

Paiva (2008) and WU (2005) state that when a response maximization is wished, the transformation formula is shown in expression 4:

$$
d i=\left\{\begin{array}{cc}
0 & \hat{Y}_{i}<L S L \\
{\left[\frac{\hat{Y}_{i}-L i}{T i-L i}\right]^{R}} & L_{i} \leq \hat{Y}_{i} \leq T_{i} \\
1 & \hat{Y}_{i}>T_{i}
\end{array}\right.
$$

Where: $\mathrm{L}_{\mathrm{i}}, \mathrm{T}_{\mathrm{i}}$ and $\mathrm{H}_{\mathrm{i}}$ are, respectively, the values of major, minor and acceptable target for the i response.

The $\mathrm{R}$ value, in expression 4, indicates a preponderance of the superior limit (LSL). Values higher than unity should be used when the response $\left(\mathrm{Y}_{\mathrm{i}}\right)$ increases rapidly above $\mathrm{L}_{\mathrm{i}}$. Therefore, $\mathrm{d}_{\mathrm{i}}$ increases slowly, while the response value is being maximized. Consequently, to maximize $\mathrm{D}$, the i response must be much larger than $\mathrm{L}_{\mathrm{i}}$. One can choose $\mathrm{R}<1$, when it is critical to find values for the response below the fixed limits.

In cases where the objective is to reach a target value, the transformation formulation stops being unilateral and becomes bilateral. The bilateral formulation, represented by expression 5, occurs when the interest response has two restrictions: one maximum and the other one minimum.

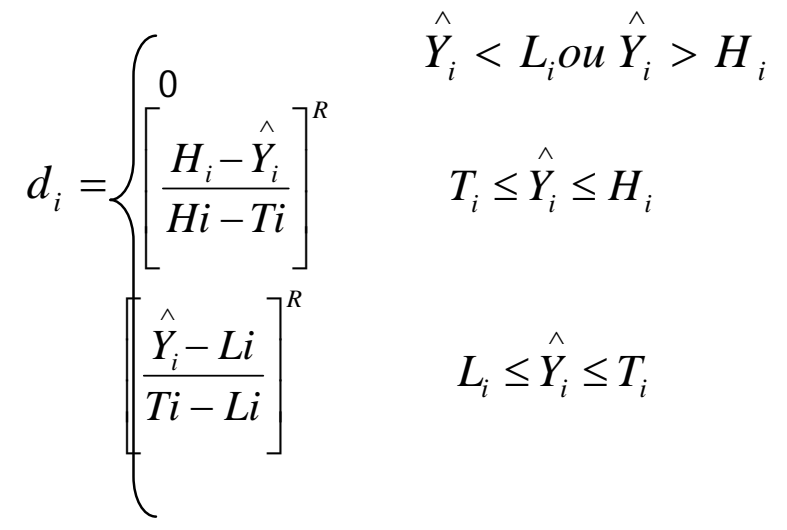

\subsubsection{Generalized Reduced Gradient Method (GRG)}

The Generalized Reduced Gradient method (GRG) has its structure based on an algorithm for solving nonlinear programming problems with constraints. Basically, the method provides only the use of linear or non-linear constraints of equality. However, for situations where the constraints are inequalities, solves the problem by introducing slack variables (if the constraint is of type $\leq$ ), or excess variables (in the case of restrictions of the type $\geq$ ). The GRG is an algorithm applied 
to optimization problems and was developed by Leon Lasdon, University of Texas at Austin, and Allan Waren, Cleveland State University. For optimization through the Generalized Reduced Gradient Algorithm (GRG), you can use Microsoft Excel Solver, which is used for optimizing nonlinear problems, through this method (SACOMAN, 2012). Microsoft Excel Solver uses iterative numerical methods involving assessment values for the adjustable cells and observes the results calculated by cells of restrictions. Each attempt is called an interaction and, in a trial, -and-error approach would require an extremely long time (especially for problems involving several adjustable cells and constraints). However, the Microsoft Excel Solver performs comprehensive analysis of observed results and change fees as are varied to guide the selection of new evaluation values.

The Genetic Algorithms (GA) have a wide application in many scientific areas, among which may be mentioned problems solutions optimization, machine learning, developing strategies and mathematical formulas, analysis of economic models, engineering problems, diverse applications in biology as simulation of bacteria, immune systems, ecosystems, discovery of format and properties of organic molecules (ZINI, 2009).

According to Holland (1975), the fittest individuals have a greater number of descendants, unlike those individuals least able. The requirements for the implementation are:

- Representations of possible solutions of the problem in the form of a genetic code;

- Initial population containing diverse enough to allow the algorithm to combine features and produce new solutions;

- Existence of a method to measure the quality of a potential solution;

- A combination of solutions to generate new individuals in the population;

- A choice of solutions that will remain in the population or it will be removed;

- A procedure to introduce periodically changes to some solutions. In this way the diversity of the population and the possibility to produce innovative solutions to be evaluated on criteria of selection of the fittest.

The basic principle of genetic operators is to transform the population through successive generations, extending the search to reach a satisfactory result. Genetic operators are necessary for the population if diversify and keep the adaptation features acquired by previous generations. Through the crossing are created new individuals, mixing characteristics of two parents. This mixture is done trying to imitate the reproduction of genes into cells and the result of this operation is an individual that potentially combine the best features of individuals used as base (HOLLAND, 1975).

\section{Materials E Methods}

\subsection{Material, Factors Selection and Experimental Organization}

The drawn steel wire is a product widely used in mechanical construction, which is the raw material used for the manufacture of various products such as: screws; chains; bearings and covers for automotive candles. This product has a great demand of consumers in the world, because they are used in machines in various sectors and especially by the automotive industry.

The spring steel SAE 9254, has chemical composition equivalent to DIN 54SiCr6, and steel is a steel chromesilicon, which is hardened and tempered and subsequently deformed the cold (PAULA, 2013). You can observe this for being a spring steel contains alloying elements such as Silicon, chromium and manganese. This is due to the characteristic of these elements in increasing the hardness of steel. In addition, Yamada (2007) demonstrated that the ideal percentage of Silicon in order to obtain the best resistance to permanent deformation is above $1 \%$.

To obtain the martensite steel must be non and the chemical composition and grain size of the material influence directly on hardenability of material and it is desirable that the present percentage of steel C between $0.2 \%$ to $0.6 \%$. In addition, some alloying elements increase the hardenability of steel, such as $\mathrm{Cr}$, Mn e Ni (YAMADA, 2007).

The material used in this work was the SAE 9254 steel wire, cold drawn, with $3.00 \mathrm{~mm}$ and $5.00 \mathrm{~mm}$ diameter. Chemical analysis was carried out in the chemical laboratory of the company funding the research, using optical emission spectrometer ARL brand. The results are presented in table 1.

\begin{tabular}{|c|c|c|c|c|c|c|c|c|c|c|c|}
\hline Chemical Elements & $\mathbf{C}$ & $\mathbf{M n}$ & $\mathbf{S i}$ & $\mathbf{P}$ & $\mathbf{S}$ & $\mathbf{C r}$ & $\mathbf{N i}$ & $\mathbf{M o}$ & $\mathbf{C u}$ & $\mathbf{A l}$ & $\mathbf{V}$ \\
\hline$(\%)$ & 0.554 & 0.64 & 1.22 & 0.022 & 0.018 & 0.58 & 0.04 & 0.03 & 0.01 & 0.009 & 0.005 \\
\hline
\end{tabular}

Table 1: Chemical Composition (SAE 9254)

\subsection{Choice of Orthogonal Arrangement}

The choice of the most appropriate orthogonal arrangement for the situation was based on the number of factors studied. As in this case it would be necessary to study four factors and suspected of the existence of two interactions, the orthogonal $\mathrm{L}_{8}$ arrangement was chosen (shown in table 2). 


\begin{tabular}{|c|c|c|c|c|c|c|c|}
\hline \multirow{2}{*}{ Experiments } & \multicolumn{9}{|c|}{ Columns } \\
\cline { 2 - 8 } & $\mathbf{1}$ & $\mathbf{2}$ & $\mathbf{3}$ & $\mathbf{4}$ & $\mathbf{5}$ & $\mathbf{6}$ & $\mathbf{7}$ \\
\hline 1 & 1 & 1 & 1 & 1 & 1 & 1 & 1 \\
\hline 2 & 1 & 1 & 1 & 2 & 2 & 2 & 2 \\
\hline 3 & 1 & 2 & 2 & 1 & 1 & 2 & 2 \\
\hline 4 & 1 & 2 & 2 & 2 & 2 & 1 & 1 \\
\hline 5 & 2 & 1 & 2 & 1 & 2 & 1 & 2 \\
\hline 6 & 2 & 1 & 2 & 2 & 1 & 2 & 1 \\
\hline 7 & 2 & 2 & 1 & 1 & 2 & 2 & 1 \\
\hline 8 & 2 & 2 & 1 & 2 & 1 & 1 & 2 \\
\hline
\end{tabular}

Table 2: Orthogonal Arrangement L8

The numbers 1 and 2 in the interior of table 2 refer respectively to the low and high levels of each factor. The allocation of each factor in the respective columns was made using the linear Taguchi graph shown in Figure 5.

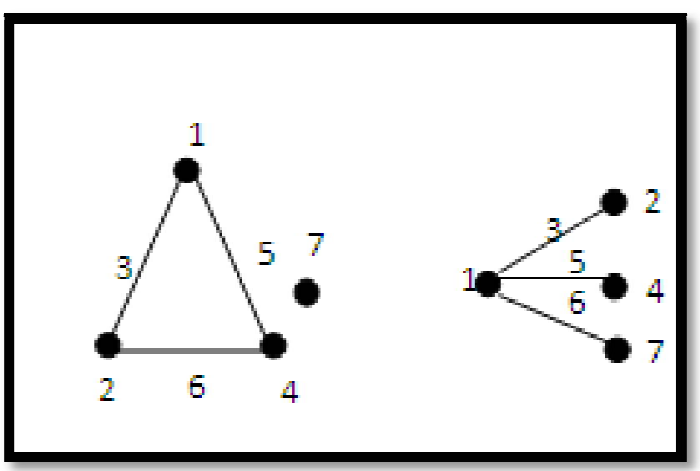

Figure 5: Linear Chart ( Source: Ross, 1995)

In columns 1,2, 4 and 6, the four factors to be studied were placed. Column 3 results from the interaction between the factors of columns 1 and 2; Column 5 results from the interaction between the factors of columns 1 and 4 . Column 7 was reserved to estimate the experimental error, necessary to verify the significance of the factors. However, in this study will not be studied as interactions.

\subsection{Selection of Factors, Response Variable and Choice of Array of Design Of Experiments}

For the selection of the factors raised the possible causes that could influence the Tensile strength (in MPa), Area reduction (in \%) and Hardness (in $\mathrm{BH}$ ) of wires, being selected the following:

- Speed of passage of wire inside the oven (in $\mathrm{m} / \mathrm{s}$ )- factor $\mathrm{A}$;

- Tempering temperature $\left(\right.$ in $\left.^{\circ} \mathrm{C}\right)$ - Factor $\mathrm{B}$;

- Polymer Concentration (in \%) (Quenching medium) - Factor C;

- Diameter (in mm)-Factor D.

The selection of the levels of the factors was based on the actual condition of the process (the minimum and maximum for all factors).

For experiments planning accomplishment, reduced variables $(\beta)$ were used rather than physical variables (real adjustments) of investigated factors, in order to preserve the confidential data of the company which funds the research. Variables reduction was calculated according to Montgomery and Runger (2003), using the physical value ( $\alpha$ ) that one wants to test subtracted from the mean $(\mu)$ between the minimum and maximum of factors adjustments. The result was divided by half the range (R) between the minimum and maximum values of factors adjustment. Thus, the reduced variables dimensionality was restricted to the range [-1 to 1 ], according to expression 6.

$\beta=\frac{\alpha-\mu}{\frac{R}{2}}$

In table 3, it is shown the relationship between adjustment levels of physical variables and variables, used for calculating the significance test to be carried out later.

\begin{tabular}{|c|c|c|}
\hline Input (factors) & Physical units & Values (reduced variables) \\
\hline Speed (in m/s) & Minimum/ Maximum & $-1 / 1$ \\
\hline Tempering temperature (in ${ }^{\circ}$ C) & Minimum/ Maximum & $-1 / 1$ \\
\hline Polymer Concentration (in \%) & Minimum/ Maximum & $-1 / 1$ \\
Diameter (in mm) & $3.00 / 5.00$ & $-1 / 1$ \\
\hline
\end{tabular}

Table 3: Physical Variables and Reduced Variables $(B)$ 
Important note: It is necessary to clarify that the standardized variable (or reduced variable) always uses the limits from -1 to 1 . However, the Taguchi method always uses the configuration from 1 to 2 . In this case, the standardized variable (-1) refers to the value 1 (used in the Taguchi method) and similarly, the standardized variable (1) refers to the adjustment 2 (used in the Taguchi method), that is, the methods only express with these values the minimum adjustments and of the factors studied. In this study, the original denomination used in each method was maintained.

\section{Sequence of Experiments, Results and Statistical Analysis}

In table 4 are the order in which the experiments were executed, its settings and adjustments the experimental results of Tensile strength, Area reduction and Hardness (responses).

\begin{tabular}{|c|c|c|c|c|c|c|}
\hline $\begin{array}{c}\text { Speed } \\
\text { (column 1) }\end{array}$ & $\begin{array}{c}\text { Tempering } \\
\text { Temperature } \\
\text { (column 2) }\end{array}$ & $\begin{array}{c}\text { Polymer } \\
\text { Concentration } \\
\text { (column 4) }\end{array}$ & $\begin{array}{c}\text { Diameter } \\
\text { (column 7) }\end{array}$ & $\begin{array}{c}\text { Tensile } \\
\text { strength } \\
\text { (MPa) }\end{array}$ & $\begin{array}{c}\text { Area } \\
\text { reduction } \\
\text { (\%) }\end{array}$ & $\begin{array}{c}\text { Hardness } \\
\text { (BH) }\end{array}$ \\
\hline 1 & 1 & 1 & 1 & 2149 & 50 & 608 \\
\hline 1 & 1 & 2 & 2 & 1949 & 56 & 550 \\
\hline 1 & 2 & 1 & 2 & 1771 & 47 & 500 \\
\hline 1 & 2 & 2 & 1 & 1927 & 58 & 544 \\
\hline 2 & 1 & 1 & 2 & 1980 & 41 & 558 \\
\hline 2 & 1 & 2 & 1 & 2136 & 51 & 603 \\
\hline 2 & 2 & 1 & 1 & 1924 & 58 & 544 \\
\hline 2 & 2 & 2 & 2 & 1787 & 44 & 506 \\
\hline
\end{tabular}

Table 4: Adjustments the Experimental Results of Tensile Strength, Area Reduction and Hardness

Factors significance was tested at a 95\% confidence level ( $p<0.05$ ). This analysis was carried out separately so that factors significance for Tensile strength, Area reduction and Hardness. For Tensile strength could be verified, as shown in Table 5.

\begin{tabular}{|c|c|c|}
\hline Terms & Coefficient & P-value \\
\hline Constant & 1952.88 & 0.000 \\
\hline (A: Speed) & -3.87 & 0.590 \\
\hline (B: Tempering Temperature) & 100.63 & 0.001 \\
\hline (C: Polymer Concentration) & 3.13 & 0.661 \\
\hline (D: Diameter) & 81.13 & 0.001 \\
\hline
\end{tabular}

Table 5: Significance Test for Tensile Strength, by

Means of the Minitab Statistical Software

Considering only the influential factors to the construction of the mathematical model for Tensile strength (as shown in Table 5), the model will be (7):

Tensile strength $=1952.88+100.63$ (Tempering Temperature) +81.13 (Diameter)

Table 5 shows the test of significance. With it, you can see that the influential factors with $95 \%$ confidence were Tempering Temperature and diameter. For this test of significance if obtained a coefficient of determination adjusted from $98.28 \%$ and a standard deviation of $18.22 \mathrm{MPa}$. The value of the coefficient of determination demonstrates that there is a great precision in the statistical test, because the value indicates the existence of high relationship between the studied factors and the results obtained.

As shown in Figure 6 you can see that the Tensile strength increases when the Tempering Temperature is on the lowest setting (adjust -1), because the lower Tempering Temperature generates a higher thermal shock that causes the temperature in steel wire is more severe, causing an increase in your hardness and consequently this generates an increase in Tensile strength. You can also notice that the experimental setting with the smaller diameter (adjust -1) generates the highest tensile strength, this is explained because the smaller the diameter of the steel-wire there will be the greatest depth of hardening of the surface to the nucleus and the higher the Hardening depth more resistant will become. This only applies in this case studied in this research. 


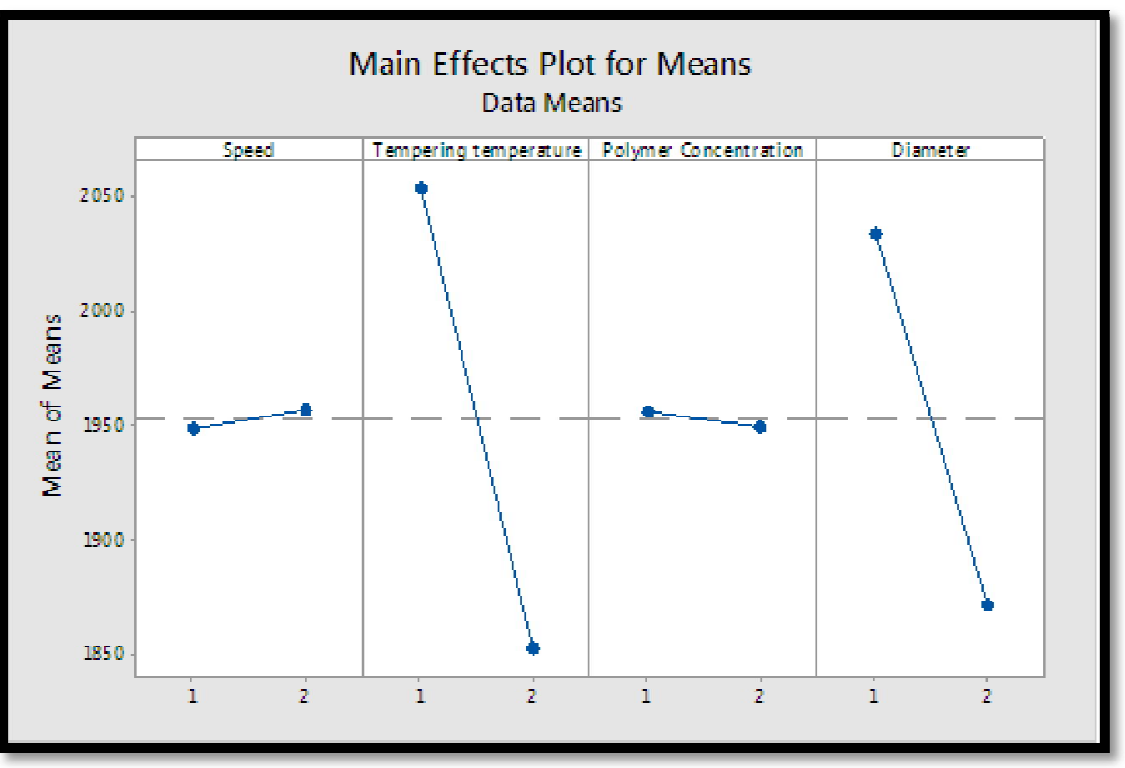

Figure 6: Main Effects Plot for Means of Tensile Strength

In order to measure the variation between the factors, the signal noise ratio was calculated following the methodology proposed by Phadke (1989) and Souza et al. (2011). The relationship "Greater is better" was adopted in this study, because it is intended in this research to find the conditions of adjustment of factors that increase the resistance of steel wire.

Through the noise signal ratio method, it was found that the adjustments of the factors that provide the smallest variation were: Factor A (Speed) at level 2; Factor B (Tempering Temperature) Level 1; Factor C (Polymer Concentration) at level 1; Factor D (Diameter) at level 1 (Figure 7).

The ratio $(\mathrm{S} / \mathrm{N})$ is inversely proportional to the variation, that is, the higher its value, the lower the variability of the experimental condition of the process. It is known that the less variation the process obtains the better quality.

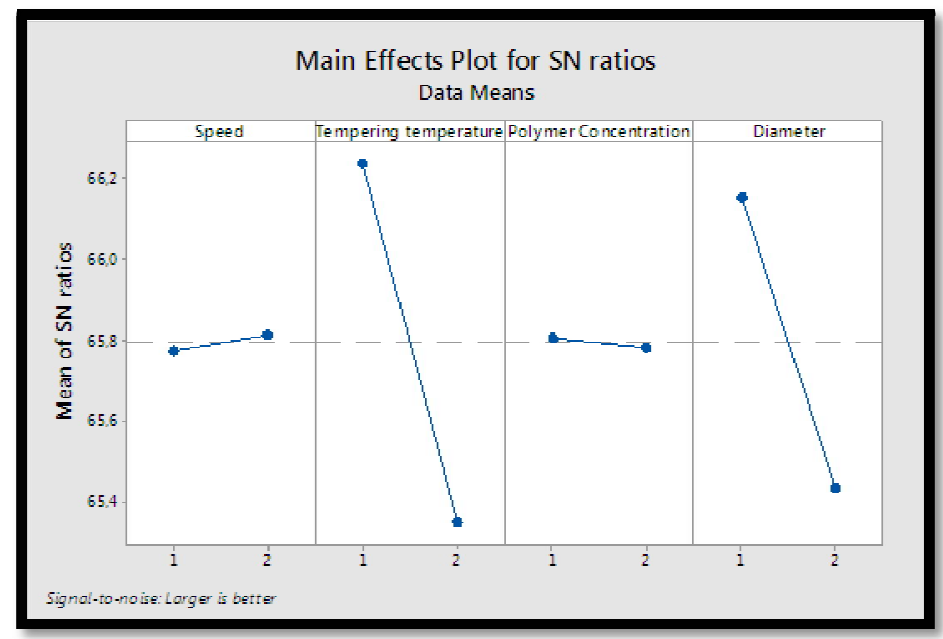

Figure 7: Main Effects Plot for SN Ratios (S/ N)

Factors significance was tested at a 95\% confidence level ( $p<0.05$ ). This analysis was carried out separately so that factors significance for Area reduction. For Area reduction could be verified, as shown in Table 6.

\begin{tabular}{|c|c|c|}
\hline Terms & Coefficient & P-value \\
\hline Constant & 50.63 & 0.000 \\
\hline (A: Speed) & 2.13 & 0.404 \\
\hline (B:Tempering Temperature) & -1.12 & 0.643 \\
\hline (C: Polymer Concentration) & -1.63 & 0.512 \\
\hline (D: Diameter) & 3.63 & 0.197 \\
\hline
\end{tabular}

Table 6: Significance Test for Area Reduction, by Means of the Minitab Statistical Software

Analyzing Table 6 it was possible to observe that none of the factors is influential for the mechanical property Area reduction. Therefore, in this case, the next analyses for this mechanical property will not be carried out and the mathematical model will not be created. 
Factors significance was tested at a 95\% confidence level ( $\mathrm{p}<0.05$ ). This analysis was carried out separately so that factors significance for Hardness. For Hardness could be verified, as shown in Table 7.

\begin{tabular}{|c|c|c|}
\hline Terms & Coefficient & P-value \\
\hline Constant & 551.63 & 0.000 \\
\hline (A: Speed) & -1.12 & 0.622 \\
\hline (B:Tempering Temperature) & 28.13 & 0.001 \\
\hline (C: Polymer Concentration) & 0.88 & 0.699 \\
\hline (D: Diameter) & 23.13 & 0.002 \\
\hline
\end{tabular}

Table 7: Significance Test for Hardness, by Means of the Minitab Statistical Software

Considering only the influential factors to the construction of the mathematical model for Hardness (as shown in Table 7), the model will be (8):

Hardness $=551.63+28.13$ (Tempering Temperature) +23.13 (Diameter)

Table 7 shows the test of significance. With it, you can see that the influential factors with $95 \%$ confidence were Tempering Temperature and diameter. For this test of significance if obtained a coefficient of determination adjusted from $97.79 \%$ and a standard deviation of $5.81 \mathrm{BH}$. The value of the coefficient of determination demonstrates that there is a great precision in the statistical test, because the value indicates the existence of high relationship between the studied factors and the results obtained.

As shown in Figure 8 you can see that the Hardness increases when the Tempering Temperature is on the lowest setting (adjust -1), because the lower Tempering Temperature generates a higher thermal shock that causes the temperature in steel wire is more severe, causing an increase in hardness. You can also notice that the experimental setting with the smaller diameter (adjust -1) generates the highest hardness, this is explained because the smaller the diameter of the steel-wire there will be the greatest depth of hardening of the surface to the nucleus. This only applies in this case studied in this research.

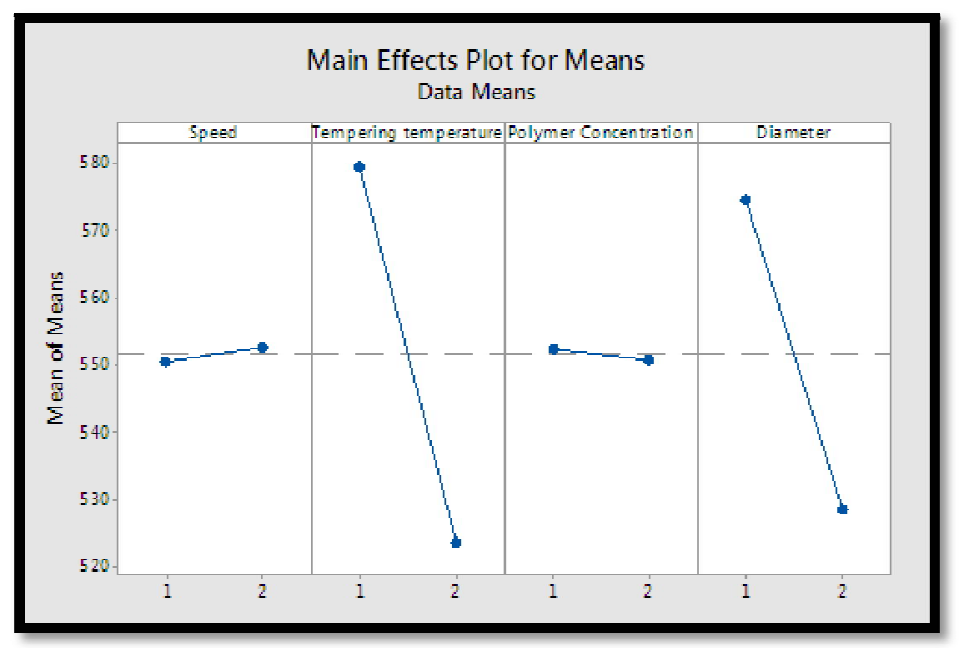

Figure 8: Main Effects Plot for Means of Hardness

In order to measure the variation between the factors, the signal noise ratio was calculated following the methodology proposed by Phadke (1989) and Souza et al. (2011). The relationship "Greater is better" was adopted in this study, because it is intended in this research to find the conditions of adjustment of factors that increase the resistance of steel wire.

Through the noise signal ratio method, it was found that the adjustments of the factors that provide the smallest variation were: Factor A (Speed) at level 2; Factor B (Tempering Temperature) Level 1; Factor C (Polymer Concentration) at level 1; Factor D (Diameter) at level 1 (Figure 9).

The ratio $(\mathrm{S} / \mathrm{N})$ is inversely proportional to the variation, that is, the higher its value, the lower the variability of the experimental condition of the process. In this study, the signal-to-noise ratio for resistance and hardness were equal because these two mechanical properties are correlated. The higher the hardness, the greater the resistance of the material. 


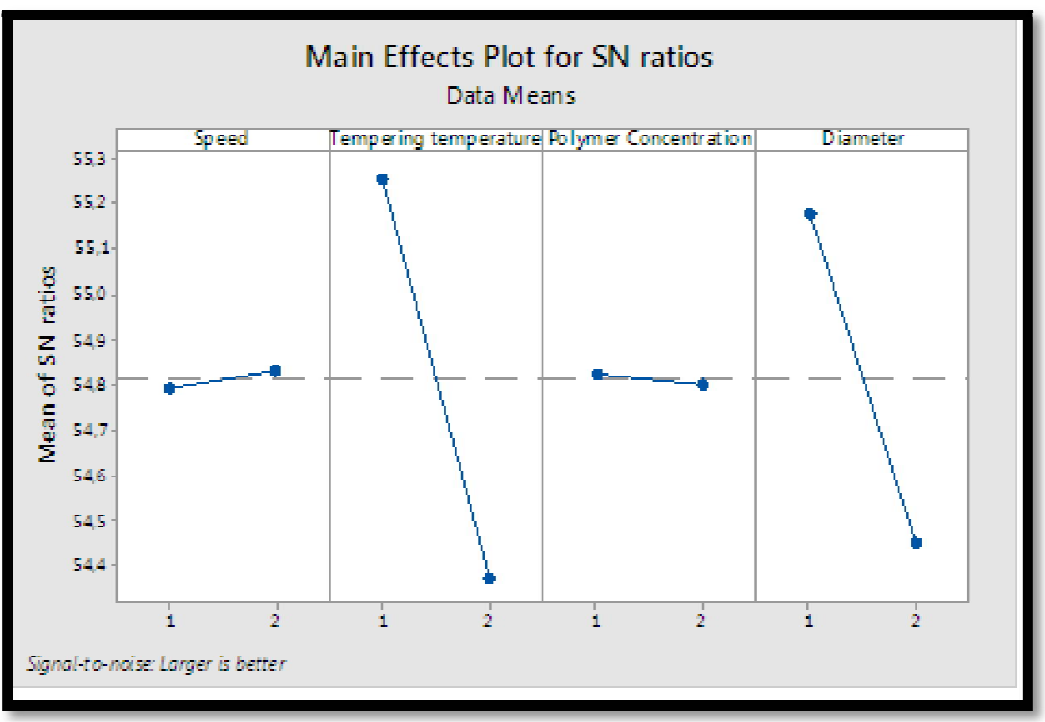

Figure 9- Main Effects Plot for SN Ratios (S/ N)

\section{Application of Desirability Function for Optimization}

For process optimization by means of desirability function, firstly, it was necessary to formulate the specifications required for the Tensile strength, Area reduction and Hardness. In this case, it is desired that the Tensile strength and hardness be as large as possible and the area reduction be the smallest possible.

The composite desirability (D) is the overall index calculated from combination of each response variables processed through a geometric mean and this index is responsible for showing the best condition to optimize all responses variables at the same time. To obtain the highest possible value for $\mathrm{D}$, which reflects in the best condition of response variables in relation to their specifications care (displayed in Figure 10), the best adjustments using factors reduced variables [1 to 2] are:

- $\quad$ Speed, adjusted in 1.0;

- Tempering Temperature, adjusted in 1.0;

- Polymer Concentration, adjusted in 1.0;

- Diameter, adjusted in 1.0.

-

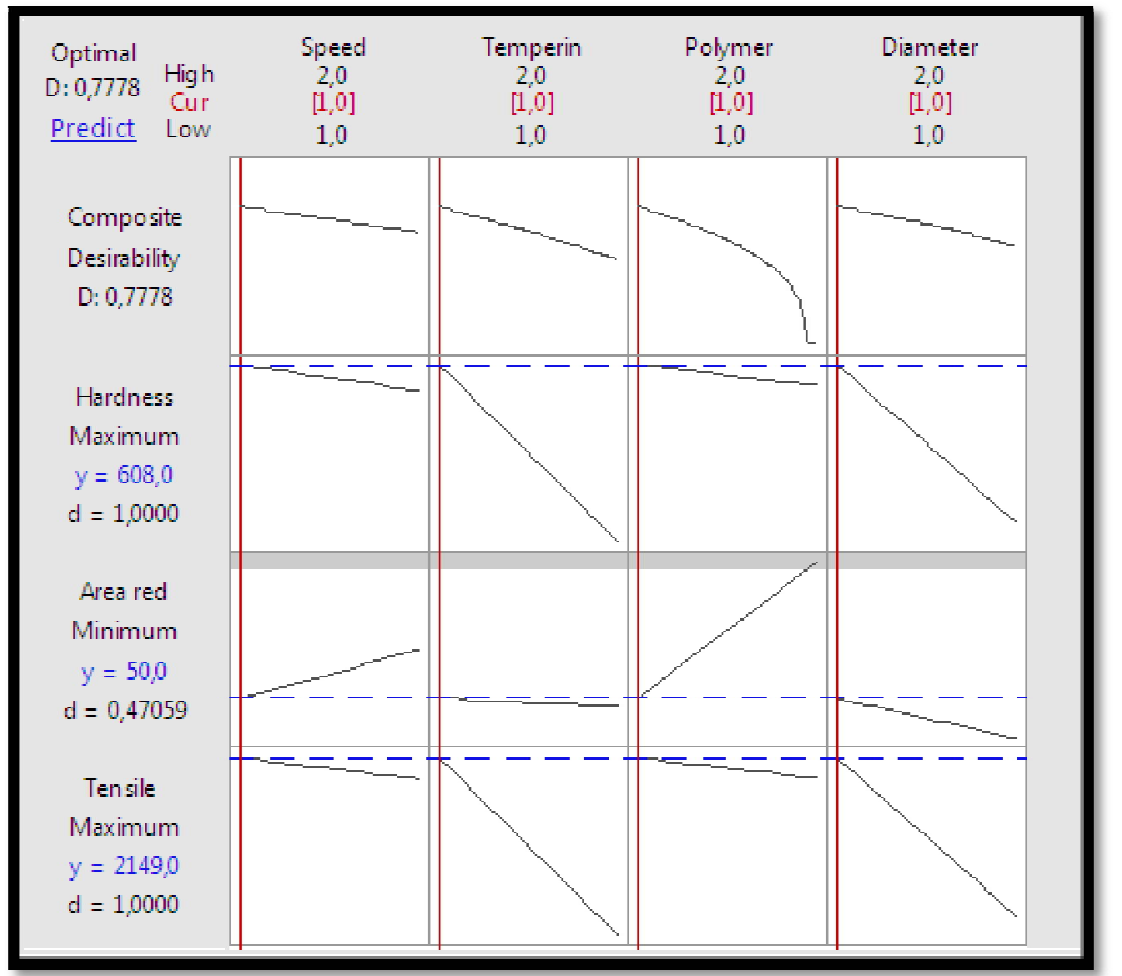

Figure 10: Desirability Function Applied In Multiple Responses (Minitab Statistical Software)

Looking at Figure 10, it can be seen that D value belonging to [0-1] interval, is maximized when all responses are close to their specifications, for the closer D is of 1 , the closer the original responses will be of their respective specification. The optimal general point of the system is the optimum point achieved by geometric mean maximization 
calculated from individual desirability functions (d), which in this case are values for each one of response variables given below:

- For response variable called hardness, $\mathrm{d}=1.00$;

- For response variable called Area reduction, $d=0.47$. However, it is important to remember that the factors were not considered influential for this variable response. Therefore, the found value of " $\mathrm{d}$ " is not considered significant.

- For response variable called Tensile strength, $\mathrm{d}=1.00$;

The values obtained for desirability $(\mathrm{D}=0.7778)$ and individual desirability $(\mathrm{d})$, show that the process was well optimized. It is important to emphasize that the value of " $\mathrm{D}$ " was not high because the factors investigated were not influential in the variable response area reduction. Thus, it was possible to find that values obtained for this optimized condition are in accordance with required specifications and are:

- $\quad$ For hardness $(\mathrm{y}=608 \mathrm{BH})$;

- For Area reduction ( $\mathrm{y}=50 \%)$.

- For Tensile strength $(\mathrm{y}=2149 \mathrm{MPa})$.

\section{Optimization Using Generalized Reduced Gradient (GRG)}

To the optimization of the process through the application of method Generalized Reduced Gradient (GRG) it was used the Solver tool contained in Excel software. In Table 8 in the programming Worksheet are all information necessaries for the development and application of optimization method.

\begin{tabular}{|c|c|c|c|}
\hline Tensile strength & Constant & Tempering Temperature & Diameter \\
\hline & 1952,88 & 100,63 & 81,13 \\
\hline & $\begin{array}{c}\text { Adjustment } \\
\text { Factors }\end{array}$ & 1 & 1 \\
& $\begin{array}{c}\text { limits of the } \\
\text { factors } \\
\text { (in standardized } \\
\text { variable) }\end{array}$ & -1 (Standardized variable) & 1 (Standardized variable) \\
\hline & $\begin{array}{c}\text { Objective } \\
\text { Function }\end{array}$ & \multicolumn{2}{|c|}{$=$ Maximize $\mathrm{B}_{2}+\left(\mathrm{C}_{2} * \mathrm{C}_{4}\right)+\left(\mathrm{D}_{2} * \mathrm{D}_{4}\right)$} \\
\hline $\begin{array}{c}\text { Specification of } \\
\text { mechanical } \\
\text { property }\end{array}$ & $\begin{array}{c}2130 \mathrm{Mpa} \\
\text { (Minimal) }\end{array}$ & Model prediction & $2135 \mathrm{Mpa}$ \\
\hline
\end{tabular}

Table 8: Worksheet for Application of the Optimization Method (GRG)

6.1. Optimization by Generalized Reduced Gradient (GRG)-Quadratic Model

For the application of this method was necessary for the definition of:

- Specifications: specifications (in Table 8) concerning the response variable tensile strength limit, will be located in cells B7. In this case, what if you want to maximize the value of the tensile strength and therefore also increase the result of mechanical property hardness. As already known and this was explained earlier (in this study), there is a direct relationship between the increase of tensile strength and the increase of hardness, because the higher the resistance value, the higher the hardness value. Then, only the result of tensile strength will be optimized, because consequently the hardness obtains the best result, since what is desired is to enlarge the values of these mechanical properties.

- Decision variables: in this case, refers to the values of the settings to be afforded the best condition of meeting the specifications of the mechanical responses. In this case the corresponding cells are C3 and D3).

- Restrictions: some restrictions (in Table 8) were charged in solver, such as, the values of the factors (considered influential) Tempering Temperature and Diameter (cells C4 and D4), were restricted to a minimum and a maximum of -1 to 1 (corresponding to the reduced variable or Standardized variable). While the value of model prediction (cell D7) was restricted to specification, in relation to the mechanical property.

- Objective function: the objective function was used (C5) to maximize the value of mechanical property (desired in this process).

It was verified through the use of this optimization method the same adjustment previously found through the application of desirability, that the best adjustments are the influential factors adjusted at the high level (1.0). However, using this method, the value of the tensile strength was $2135 \mathrm{Mpa}$.

This variation of resultant values was considered acceptable and will not harm the study, since in the use of the Desirability method all the factors studied and the use of the GRG method were used only the influential factors. This difference was not significant for this process.

\section{Conclusion}

It was concluded that with the application of the Taguchi Method it was possible to reduce the number of experiments to be carried out and thus it was possible to reduce the costs significantly. If instead of using the Taguchi Method a complete matrix $2^{4}$ would be required to perform 16 experiments with at least one repetition for each situation 
(so that it was possible to calculate the standard error). With this, 32 experiments would be carried out. In this case, with the use of the Taguchi method, the quantity of experiments was reduced to 8 experiments (without the need repetition), which represented the reduction of $75 \%$ in the costs of experimentation.

The tempering temperature and diameter are the factors that cause the increase or reduction of the variable responses' tensile strength and hardness of drawn steel wire SAE $9254(3.00 \mathrm{~mm}$ and $5.00 \mathrm{~mm})$ during the tempering process. It was also concluded that the factors investigated have not influence on the variable response area reduction.

It was concluded that the tensile strength and hardness increases when the tempering temperature is adjusted in 1 (low level) and diameter is adjusted in 1 (low level). This is because the lower tempering temperature generates a higher thermal shock that causes the temperature in steel wire is more severe, causing an increase in your hardness and consequently this generates an increase in tensile strength and hardness. The smaller diameter generates the highest tensile strength and hardness because the smaller the diameter of the steel-wire there will be the greatest depth of hardening of the surface to the nucleus and the higher the hardening depth more resistant will become. However, it is important to note that this only occurred in this study.

Through the use of the method Desirability was found the best tweaks of the influential factors to obtain the best condition were processing: Speed adjusted in 1.0, Tempering Temperature adjusted in 1.0, Polymer Concentration adjusted in 1.0 and Diameter adjusted in 1.0. That is, the best fit is all factors adjusted at the low level to obtain the best results from the response variables.

It was verified that the use of this optimization through the Generalized Reduced Gradient method (GRG) was the same adjustment previously found through the application of Desirability and that the variation of resultant values was considered acceptable and will not harm the study.

It was possible to conclude from the experience gained by the researcher that carried out this study that the experimental execution in an industrial environment requires a series of specific care, which are extremely important so that the proposed results can be effectively achieved.

It was also concluded that the statistical methods and optimization studied in academic environments and often employed only on a small scale of production, in research laboratories or in simulators in universities, can also be applied In an industrial environment of large scale production, contributing to the solution of complex problems and being of important value for future technological innovations in the industries.

\section{References}

i. BERGER, C.; KAISER, B. Results of very high cycles fatigue tests on helical compression springs. International Journal of Fatigue, Ohio, v. 28, n. 1, p. 1663-1700, oct 2006.

ii. CALLISTER JR., W. D.; RETHWISCH, D. G. Materials science and engineering: an introduction. 8. ed. New York: LTC, 2012.724 p.

iii. CORREIA, E. A. S.; CARDOZA, J. A. S. Design of experiments in the productive process using Taguchi method. Production and Operations Management Systems, Bauru, v.6, n. 1, p. 55-66, jan 2011.

iv. CHIAVERINI, V. Steels and cast irons. 7. Edition. São Paulo: Brazilian Association of Metallurgy and materials, 2012.600 p.

v. DERRINGER, G., SUICH, R. Simultaneous Optimization of Several Response Variables, Journal of Quality Technology, v 12, n 4, p.214-219, 1980.

vi. GABARDO, J. F. Study of toughness tool steel H13. 2008. 112 p. Dissertation (master's degree in mechanical engineering)- Federal University of Paraná, Curitiba, 2008.

vii. HOLLAND, J. H. Adaptation in natural and artificial systems. 1. ed. Cambridge: MT press, $1975.500 \mathrm{p}$.

viii. LIMA, V. B. S.; BALESTRASSI, P. P.; PAIVA, A. P. Performance optimization of broadband radio frequency amplifiers: an experimental approach, Production, v. 21, n. 1, p. 118-131,jan/ march, 2011.

ix. MONTGOMERY, D. C.; RUNGER, G. C. Applied statistics and probability for engineers, 2ª Edition, Publisher LTC, 2003, 230-320 p.

x. MONTGOMERY, D. C.; RUNGER, G. C. Applied statistics and probability for engineers. 4. ed. New York: LTC, 2009. $514 \mathrm{p}$.

xi. NETO, B. B.; SCARMINIO, I. S.; BRUNS, R. E. How to make experiments: research and development in science and industry, 3a Edition, Publisher Unicamp, 2007, 480 p.

xii. PAIVA, E. J. Manufacturing optimization with multiple Responses based on capacity indexes, Thesis, Federal University of Itajubá, 2008, 117 p.

xiii. PAULA, R. F. V. Helical springs fatigue of automobile suspension. 2013. 145 p. Dissertation (master's degree in mechanical engineering)- State University Paulista, Guaratinguetá, 2013.

xiv. PHADKE, M. S. Quality engineering using robust design, 1'st edition, New York, Prentice Hall, 1989, 333 p.

xv. ROBIN; A.; ROSA, J. L., SILVA, M. B. Electrodeposition and characterization of Cu-Nb composite coatings. Surface \& Coatings Technology, Sidney, v. 205, n. 1, p. 2152-2159, oct 2010.

xvi. ROSA, J. L.; ROBIN, A.; SILVA, M. B.; BALDAN, C. A.; PERES, M. P. Electrodeposition of copper on titanium wires: Taguchi experimental design approach. Journal of Materials Processing Technology, Sydney, v. 209, n. 1, p. 11811188, jan 2009.

xvii. ROSS, P. J. Taguchi techniques for quality engineering, $2^{\text {nd }}$ edition, New York, McGraw-Hill Professional, 1995, 329 p. 
xviii. SACOMAN M. A. R.; Project optimization using IBC, Solver and Excel. In: BRAZILIAN CONGRESS OF EDUCATION AND ENGINEERING, 1., 2012, Belém- Brasil, 2012. Impres. 1-12 p.

xix. SILVA, H. A.; SILVA, M. B. Application of design of experiments (DOE) in the tube welding zircaloy-4; Production \& Engineering, v. 1, n. 1, p. 41-52, set. / dec. 2008.

xx. [20] SOUZA, H. J. C.; MOYSES, C. B.; PONTES, F. J.; DUARTE, R. N.; SILVA, C. E. S.; ALBERTO, F. L.; FERREIRA, U. R.; SILVA, M. B. Optimization Molecular assay optimized by Taguchi experimental design method for venous thromboembolism investigation. Molecular and Cellular Probes, Sidney, v.25, n. 1, p. 231-237, dez 2011.

xxi. [YAMADA, Y. Material for springs. Japan Society of spring Engineers, Tokio, v. 1, n. 1, p. 377-384, dec 2007.

xxii. WANG, J.; WAN, W. Application of desirability function based on neural network for optimizing biohydrogen production process, international journal of hydrogen energy, v.34, p. 1253-1259, 2009.

XXIII. WU, F. C. optimization of correlated multiple quality characteristics using desirability function. Quality engineering, v 17, n 1, pp. 119-126, 2005.

xxiv. ZINI, E. O. C. Genetic algorithm specializes in solving problems with continuous variables and highly restricted. 2009. 100 p. Dissertation (master's degree in electrical engineering)- State University Paulista, 2009. 